\title{
VULGARIZACIÓN Y DESTRUCCIÓN DEL HABLA ANDALUZA EN LA TRADUCCIÓN LITERARIA
}

\author{
VULGARIZATION AND DESTRUCTION OF ANDALUSIAN SPEECH IN LITERARY \\ TRANSLATION
}

\section{VULGARIZAÇÃO E DESTRUIÇÃO DO FALAR ANDALUZ NA TRADUÇÃO LITERÁRIA}

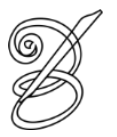 \\ Luis Carlos RAMOS-NOGUEIRA* \\ Universidade de Brasília, Brasil
}

\begin{abstract}
Resumen: La traducción literaria en el par lingüístico español-portugués supone afrontar retos que van desde las cuestiones lingüísticas relacionadas con la proximidad entre ambas lenguas hasta la toma de decisiones por parte del traductor. Este artículo pretende centrarse en este último, discutiendo y poniendo de relieve la postura ética del profesional de la traducción frente al fenómeno de las superposiciones de lenguas. Para tal fin, en este trabajo se ha elegido un fragmento de La Sombra del Viento, novela escrita originalmente en español por Carlos Ruiz Zafón, con el objetivo de analizar, a la luz de los postulados de las tendencias deformantes de Berman (2014 [1999]), la actuación de dos traductores implicados en dicha labor. En concreto, se ha puesto el acento en las reflexiones de este teórico en lo que respecta al borramiento de las superposiciones de lenguas y la destrucción de las redes lingüísticas vernáculas. El análisis, de cariz contrastivo, ha centrado la atención en las soluciones ofrecidas por los traductores en portugués de Brasil y de Portugal para el problema del habla andaluza que se ha identificado en el modo de comunicarse de uno de los personajes. Los resultados no podrían haber sido un ejemplo más convincente de las múltiples posibilidades de solución en el marco de la traducción literaria. Sobre todo, se ha detectado que se impone un conjunto de peculiaridades (omisión, transformación, homogeneización, entre otras). Dicho conjunto es el que ha conducido a cada uno de los traductores involucrados a desempeñar su oficio de un modo particular. De hecho, se ha identificado una paradoja en la que cada traductor actúa de distintas formas. Todas ellas se encuentran previstas en el acervo de tendencias deformantes de Berman.
\end{abstract}

Palabras clave: Traducción literaria. Traducción ética. Superposición de lenguas. Habla andaluza. EspañolPortugués.

\begin{abstract}
Literary translation in the Spanish-Portuguese language pair assumes facing challenges in a range from linguistic issues related to the proximity between both languages to the decision-making by the translator. This article aims to focus on the latter challenge by discussing and highlighting the translation professional's ethical attitude regarding the phenomenon of language overlays. For this purpose, a fragment of La Sombra del Viento (novel originally written in Spanish by Carlos Ruiz Zafón) was chosen in order to help the analysis of the performance of two translators involved in this task in the light of the postulates of Berman's deforming tendencies (2014 [1999]). Special attention has essentially been paid to the reflections of this theorist concerning the disappearance of language overlays and the destruction of vernacular linguistic networks. The contrastive analysis focused attention on the solutions offered by the translators in Portuguese from Brazil and Portugal for the Andalusian speech problem that has been identified in the communication mode of one of the characters. The results might be a more convincing example of the multiple possibilities of solution to literary translation. Above all, the study revealed the imposition of a set of peculiarities (omission, transformation, homogenization, among others) that influenced each one of those involved in their particular way of performing their job. Actually, a paradox in which each translator acts in different ways has been identified. All of those ways are found in Berman's deforming trends collection.
\end{abstract}

Keywords: Literary translation. Ethical translation. Language overlays. Andalusian speech. Spanish-Portuguese. 
Resumo: A tradução literária no par linguístico espanhol-português supõe o enfrentamento de desafios que vão desde as questões linguísticas relacionadas à proximidade de ambas as línguas até a tomada de decisões por parte do tradutor. Este artigo pretende se concentrar neste último, discutindo e destacando a postura ética do profissional da tradução quanto ao fenômeno das superposições de línguas. Para esse fim, neste trabalho escolheu-se um fragmento de La Sombra del Viento, romance escrito originalmente em espanhol por Carlos Ruiz. Zafón, com o objetivo de analisar, à luz dos postulados das tendências deformadoras de Berman (2014 [1999]), a atuação de dois tradutores envolvidos nessa tarefa. Concretamente, privilegiaram-se as reflexões desse teórico no que diz respeito ao apagamento das superposições de línguas e à destruição das redes linguísticas vernáculas. A análise, de cunho contrastivo, manteve o foco nas soluções oferecidas pelos tradutores em português do Brasil e de Portugal para o problema da variedade andaluza que se identificou no modo de se comunicar de um dos personagens. Os resultados não poderiam haver sido um exemplo mais convincente das múltiplas possibilidades de solução no âmbito da tradução literária. Sobretudo, detectou-se que se impõe um conjunto de peculiaridades (omissão, transformação, homogeneização, entre outras). Tal conjunto foi o que levou cada um dos tradutores envolvidos a desempenhar seu ofício de um modo particular. Efetivamente, identificou-se um paradoxo no qual cada tradutor atua de diversas maneiras. Todas elas se encontram previstas no acervo de tendências deformadoras de Berman.

Palavras-chave: Tradução literária. Tradução ética. Superposições de línguas. Falar andaluz. EspanholPortuguês.

RECEBIDO EM: 04/02/2019

ACEITO EM: 31/08/2019

PUBLICADO EM: 10/2019

RAMOS-NOGUEIRA, Luis Carlos. Vulgarización y destrucción del habla andaluza en la traducción literaria. Belas Infiéis, Brasília, v. 8, n. 4, p. 35-54, 2019. 


\section{Introducción}

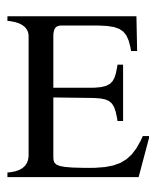

s sobradamente sabido que se ha establecido en el marco de la traducción, desde una perspectiva más generalizada, la falsa ilusión de que el traductor afrontaría menos dificultades en su labor en lo que respecta al par lingüístico español/portugués/español ${ }^{1}$. Quizás, esta creencia se haya extendido, inadvertidamente, debido al alto nivel de proximidad entre ambas lenguas.

Sin embargo, cabría reconocer que dicha proximidad es un arma peligrosa de doble filo. $\mathrm{Si}$, por un lado, la sonoridad y la grafía de ciertas palabras le puede hacer creer al traductor más incauto que hay alguna correspondencia entre la una y la otra, por otro, puede que se trate tan solo de una apreciación insuficiente por desconocimiento.

La trampa que se pone de manifiesto, quizás por desconocimiento, está principalmente, vinculada al célebre fenómeno de los falsos cognados. De ser así, la podríamos adscribir al rango lingüístico. Sin embargo, habría que tener en cuenta que, además de los elementos lingüísticos, no estaría de más apreciar los elementos extralingüísticos como la cultura, por citar un ejemplo importante.

Dicho lo cual, a modo de preámbulo, en este trabajo queremos discutir cuestiones que transcienden la lengua que se considera estándar. Pretendemos poner de relieve los problemas que conlleva la traducción de las variedades y formas lingüísticas del español al portugués de Brasil y de Portugal, en el ámbito de la traducción literaria.

Para llevar a cabo nuestra tarea realizaremos un análisis contrastivo del diálogo protagonizado por los personajes del autor catalán Carlos Ruiz Zafón (2001) en su novela de mayor éxito, a saber: La sombra del Viento, un superventas traducido a más de treinta y cinco idiomas alrededor del mundo.

Nos apoyaremos, teóricamente, en los postulados de Berman en lo que concierne a las tendencias deformantes de la traducción, resultantes de su defensa de una traducción ética. En concreto, centraremos nuestra atención en la actuación de los traductores en lo que atañe al borramiento $^{2}$ (sic.) de las superposiciones de lenguas y la destrucción o exotización ${ }^{3}$ de las redes lingüísticas vernáculas.

A fin de fundamentar la elección del fragmento literario que hemos elegido para análisis, trataremos de resumir el modus operandi del autor y el universo andaluz que brinda a su lector. 


\section{La traducción ética, según Antoine Berman}

La "traducción ética", o "traducción de la letra" por la que aboga Berman es el resultado de una serie de reflexiones que se centran con alguna exclusividad en la traducción literaria, más específicamente, en la prosa.

En la obra que nos ocupa, a saber: La traducción y la letra o el albergue de lo lejano, el estudioso francés pone de relieve una cadena de características propias que dialogan entre sí y que conforman la malla textual de la gran prosa, con todos los detalles que a ella le son inherentes. Sus postulados constituyen, en cierto modo, un reproche del autor a lo que él mismo denomina "una crítica de las teorías tradicionales que conciben el acto de traducir como una restitución embellecedora (estetizante) del sentido" (BERMAN, 2014 [1999], p.13).

La "traducción de la letra" de la que trata el título de la obra en cuestión no debe ser concebida como una traducción literal, palabra por palabra, tal y como se entiende, equivocadamente, en el área de la Traductología. El mismo Berman (2014 [1999], p.14) procura aclararlo al afirmar que "[...] traducir la "letra" de un texto no equivale de ningún modo a traducir palabra por palabra".

Filósofo, crítico literario y teórico de la Traductología, el francés Antoine Berman tiene por costumbre apropiarse de conceptos y valerse de neologismos en su escritura. De ese modo, se adueña del concepto de "letra" y lo redefine a su manera, según sus necesidades epistemológicas. En resumen, "la letra", a que se refiere en su obra, se podría conceptuar como un conjunto de dimensiones que confieren al texto literario su gran triunfo como tal. En palabras del propio autor, "la letra, son todas las dimensiones contra las cuales combate el sistema de deformación" (BERMAN 2014 [1999], p.72).

De dicho conjunto forman parte algunas estrategias del escritor del texto de origen (TO) que le confieren riqueza y elevan su estatus literario, tales como: imprimirle cierto ritmo y oralidad; jugar con la participación activa del lector al no definir ni explicitar ciertos pensamientos; servirse de términos, locuciones y proverbios para presentar rasgos de la lengua vernácula en la que está escrita la obra; crear cadenas y redes (subyacentes) de significantes; plasmar en la heterogeneidad de la obra, como un todo, la pluralidad de posibilidades de la lengua de origen (LO); crear una sistematicidad dentro del texto que establece la preferencia por ciertos tiempos verbales y tipos de oraciones subordinadas; servirse de redes lingüísticas vernáculas, que muchas veces son la representación del lenguaje oral del grupo de hablantes de la LO; poner de manifiesto la superposición de lenguas: variedades lingüísticas y dialectos. 
Traducir un texto literario tan rico en detalles se convierte, sobre todo, en el mayor reto que el traductor ha tenido que afrontar nunca. La dificultad radica en el hecho de que se le ha inculcado que traducir un texto literario significa tornarlo comprensible al lector final. Tal creencia se debe a la representación popular acerca de en qué consiste su tarea y lo que se espera de él.

Seguro del papel que le toca desempeñar, su meta es construir un texto plano y homogéneo en el que, en nombre de su "misión", no hesita en hacer nacional lo que no lo es, ni tampoco titubea en explicar lo que no carece de explicación. Se trata, pues, de destruir la "letra" en beneficio del sentido.

Así, la "ética", noción clave en la obra de Berman, radica en respetar lo extranjero. Entiéndase "extranjero" aquí, no exclusivamente como el conjunto de elementos lingüísticos y culturales propios de la lengua del TO, sino como un conjunto de aspectos del texto literario (incluidos los mencionados aspectos lingüísticos y culturales) que se deben acoger, en lugar de destruirse. En ello se encuentra el quid de la traducción ética o traducción de la letra en cuestión. Berman resume su concepción de ética en el marco de la traducción literaria en la siguiente frase: "el acto ético consiste en reconocer y en recibir al Otro en tanto Otro" (BERMAN, 2014 [1999], p.82).

Conforme a lo supuestamente exigido en la traducción ideal, los aspectos literarios que hemos mencionado con anterioridad se transforman en algo extraño ${ }^{4}$ que no cabría en el discurso "perfecto" que debe producir el texto meta (TM). Desde esta perspectiva, no queda otra opción que expurgarlos, destruirlos. Así, el camino por recorrer no podría ser otro sino la transformación de lo ajeno y molesto en algo de fácil identificación por parte del lector. Dicho de otro modo, la tarea del traductor consistiría en la sustitución de un texto supuestamente raro e imperfecto por otro, con elementos de la lengua y de la cultura meta, libre de términos, locuciones y proverbios que se desconocen, repetición de palabras, variedades lingüísticas, entre otros detalles. De esta manera, tras limpiar el texto original de sus "imperfecciones", el traductor tendría en manos un producto homogéneo y de fácil "digestión” que ofrecer al lector final. Esta operación tendría como objetivo convertir lo ajeno y extranjero en nacional, en algo que se pudiera reconocer y aceptar fácilmente. En otras palabras, se mantiene la zona de confort en la que se encuentra el lector. En ello consiste lo que Berman denomina "traducción etnocéntrica".

La traducción ética, o de la "letra", por la que aboga Berman sería aquella que no es "ni calco, ni (problemática) reproducción, sino atención dirigida hacia el juego de significantes” 
(BERMAN, 2014 [1999], p.15). Es más. Se convierte en “albergue de lo lejano" (BERMAN, 2014 [1999], p.83). Se trata, efectivamente, de abrir espacio en la lengua de traducción para que se pueda poner de manifiesto la novedad ofrecida por el TO. Desde esta perspectiva, la traducción que no le da primacía a este juego de significantes destruye, por defecto, la "letra".

\section{La sistemática de la deformación, según Antoine Berman}

Para Berman (2014 [1999]), la prosa y, sobre todo, la novela, se caracterizan por lo que él denomina "cierta informidad", resultado de una profusión de lenguas, una proliferación babélica, que se produce en la obra. Entiéndase "informidad" como la falta de forma del TO, observado desde la perspectiva etnocéntrica e hipertextual de la traducción, que ve en ello un problema que necesita corrección. Con todo, no se puede olvidar que esta heterogeneidad forma parte de la propia naturaleza de la gran prosa.

Según este autor, el problema de la traducción de la prosa es respetar su polilogía informe. Se entiende que un texto literario informe estaría naturalmente compuesto de algunos elementos considerados molestos por la tradición etnocéntrica e hipertextual de la traducción.

En opinión de Berman (op. cit.), los elementos incómodos son, en rigor, el centro de las atenciones del traductor etnocentrista e hipertextual, que toma para sí la tarea de uniformar el TM y entregar al lector una versión final desprovista de dichos elementos.

\subsection{Trece tendencias deformantes de la traducción, según Antoine Berman}

El intento de corregir, de pulir, de perfeccionar lo que el traductor considera inoportuno, dentro de una perspectiva etnocéntrica e hipertextual, sería la causa de ciertas deformaciones derivadas unas de las otras o vinculadas entre sí. Dichas deformaciones funcionan como piezas de un conjunto de estrategias para librar al TO de su supuesta imperfección.

Mayormente, el traductor lo hace de manera inconsciente, movido por una arraigada y dudosa concepción de lo que viene a ser la traducción ideal. Son trece las tendencias deformantes: 1) la racionalización; 2) la clarificación; 3) el alargamiento; 4) el ennoblecimiento; 5) el empobrecimiento cualitativo; 6) el empobrecimiento cuantitativo; 7) la homogeneización; 8) la destrucción de los ritmos; 9) la destrucción de las redes significantes subyacentes; 10) la destrucción de los sistematismos; 11) la destrucción o la exotización de las redes lingüísticas vernáculas; 12) la destrucción de las locuciones; 13) el borramiento (sic.) de las superposiciones de las lenguas (BERMAN, 2014[1999], p.58-73). 
Podríamos identificar en el tramo que hemos elegido para análisis una media docena de las tendencias deformantes de Berman. Sin embargo, preferiremos mantener el enfoque en solo tres de ellas, por relacionarse directamente con nuestro objeto de investigación y con la cuestión del espacio polilinguístico que se plasma en la malla literaria de la gran prosa, a saber: la destrucción o la exotización de las redes vernáculas; el borramiento (sic.) de las superposiciones de lenguas y la homogeneización.

\subsubsection{La destrucción o la exotización de las redes lingüísticas vernáculas}

Las redes lingüísticas vernáculas a las que se refiere Berman se pueden definir como las conexiones muy estrechas que establece una obra en prosa con la lengua original en la que ha sido creada. Consisten en tres cuestiones básicas: 1) la intención plurilingüe de la prosa requiere, forzosamente, una pluralidad de elementos vernáculos; 2) la lengua vernácula es más corporal, más icónica que la lengua koiné $e^{5}$, la lengua culta; 3) el objetivo de la prosa puede ser la retomada de la oralidad vernácula.

Así, según Berman, borrar los aspectos de la lengua vernácula es un grave atentado contra la textualidad de la obra. Dicha acción de borrar podría ocurrir a través de la supresión de los diminutivos; a través del reemplazo de los verbos activos por verbos con sustantivos como, por ejemplo, optar por 'volverse una laguna', en detrimento de la forma peruana "alagunarse"; o de la selección de sintagmas como 'habitante de Buenos Aires', en detrimento del adjetivo "porteño" (relativo a Buenos Aires).

Otra práctica común que aparece en las traducciones literarias es la de la exotización. La manera más habitual de hacerlo es aislar la palabra de la lengua vernácula a través de un procedimiento tipográfico distinto, como es el caso de las cursivas. La palabra surge en el TM, entonces, como algo raro, exótico, porque la propia presentación tipográfica lo denuncia, al mostrarla diferente de las demás. En el TO, en cambio, esta misma palabra no se destaca, ya que se presenta tipográficamente igual que el resto del texto.

Asimismo, la exotización puede asociarse a la vulgarización, al convertirse un dialecto o una variedad vernácula extranjera en un dialecto o variedad vernácula local. Para Berman es aún peor, puesto que este hecho implica la ridiculización del original. Así, la práctica común que se sirve del argot local de París para traducir el lunfardo de Buenos Aires, por ejemplo, no soluciona el problema. 


\subsubsection{El borramiento (sic) de las superposiciones de lenguas}

En opinión de Berman "toda prosa se caracteriza por superposiciones de lenguas más o menos declaradas" (BERMAN, 2014 [1999], p.71). Dichas superposiciones serían de dos tipos: dialectos que coexisten con una koiné, o varias koinai que coexisten.

En los ejemplos de este autor, serían una representación del primer caso la convivencia de diversas posibilidades del español latinoamericano con el español de España en Tirano Banderas, de Valle-Inclán y la mezcla del portugués castizo y los muchos modos de hablar del nordeste $^{6}$ de Brasil, en la obra de Guimarães Rosa. Del segundo caso se podrían citar dos ejemplos: el trabajo de Roa Bastos, en el que las lenguas orales guaraní y quechua alteran sintácticamente al español, y el caso límite de Finnegans Wake, de Joyce.

En nombre del elegante y bello discurso, la traducción tiende a borrar las superposiciones de lenguas a través de la homogeneización al nivel del registro linguístico. De este modo, se propicia que desaparezca del nuevo texto el diálogo entre lenguas y dialectos que coexisten en el original, capaz de representar las sutiles diferencias de la variedad de culturas que se manifiestan en las más diversas maneras de expresarse de los personajes.

\subsubsection{La homogeneización}

Berman (op. cit) concibe la homogeneización como el reagrupamiento de la mayor parte de las tendencias deformantes. Así que homogeneizar el texto significa hacerlo plano, libre de cualquier elemento que salga de tono, a través de la racionalización, de la clarificación, del alargamiento, de la destrucción o la exotización de las redes lingüísticas vernáculas y del borramiento (sic.) de las superposiciones de lenguas, entre otras tendencias.

Dicho de otro modo, la cualidad de heterogéneo, que se le atribuye al texto en prosa, generalmente, desaparece a través de la acción del traductor, a quien se le ha inducido a pensar que forma parte de su tarea "mejorar el texto", "limpiándolo de impurezas". Al actuar de esta manera, éste será capaz de unificar el tejido del original en todos los planos. Sin embargo, habría que tener en cuenta que la mejora del texto que se le exige al traductor, corresponde justamente al sacrificio de lo que le confiere al texto literario su identidad como tal, es decir, por su pluralidad de posibilidades.

Tras discutir los postulados de Berman con relación a las redes lingüísticas vernáculas y las superposiciones de lenguas, presentamos a continuación un ejemplo práctico en donde ocurren dichos fenómenos para, posteriormente, analizarlo. Asimismo, nos parece pertinente 
abordar algunas informaciones acerca del autor y el ambiente lingüístico y cultural del que se sirve.

\section{El universo literario de Carlos Ruiz Zafón}

Carlos Ruiz Zafón es un escritor español, de origen catalán. Su obra completa, cuyas ventas rozan la cifra de los quince millones de ejemplares, está compuesta de ocho novelas, publicadas oficialmente: El príncipe de la niebla, El palacio de la medianoche, Las luces de septiembre, Marina, La sombra del viento, El juego del ángel, El prisionero del cielo, y El laberinto de los espíritus.

El ambiente en el que se desarrollan las novelas, en su gran mayoría, es el de una España entre los años 20 y 80. Las primeras, son dramas detectivescos adolescentes, salpicados de toques de terror. El gran cambio se produce con la publicación de la La sombra del viento ${ }^{7}$, novela en la que el autor conserva el clima detectivesco a lo Agatha Christie, pero con tinte español. Esta mezcla de estrategias para la composición de una historia se convertiría rápidamente en un fenómeno mundial.

La notable transformación de su trayectoria literaria se produce a partir de La sombra del viento, dado que se puede observar, a partir de esta obra, una forma más precisa y elaborada en la comunicación e intervención de los personajes, que se presentan más maduros y poseen una irresistible atracción hacia las letras. Analizándolo con un poco más de creatividad, sería posible afirmar que el gran personaje, en realidad, pasa a ser el propio arte de escribir, representado en la figura de libreros, escritores frustrados y perseguidos, además de traductores que luchan por ganarse la vida a través de su oficio. En este ambiente, propicio para las elucubraciones y fantasía del autor, surge el personaje-filósofo Fermín Romero de Torres, de la boca de quien surgen metáforas y frases hechas.

Ruiz Zafón integra aquel grupo de escritores que parece tener el placer de disfrutar de una época y de un universo, especialmente creado con determinado propósito. Es más, parece empecinarse en que su lector se embarque con él en esa aventura.

Para que resulte verosímil su mundo ficticio, Ruiz Zafón se sirve de todos los recursos que tiene a su alcance: descripciones pormenorizadas de plazas (Plaza de Arenas/Barcelona); cafés (El Quatre Gats/Barcelona) y otros edificios (Catedral de Santa María del Mar, Castillo de Montjuic, Teatro Poliorama/Barcelona) y calles conocidas (Las Ramblas, Calle Arc del Teatre/Barcelona); cita de nombres específicos de personajes reales e importantes de la historia reciente, tales como militares (Francisco Franco), artistas (Concha Piquet, Lola Flores), 
escritores y filósofos (Ortega y Gasset), además de referirse a comidas específicas (escudella), casi todos ellos pertenecientes al universo español y sobre todo, catalán.

Sin embargo, es en el marco de la lengua en donde se puede identificar un trabajo rico en detalle, en el que se observa desde la presencia de una cantidad suficiente de frases hechas, en una profusión de paremias, colocaciones y locuciones, capaz de alimentar un enorme glosario, hasta la representación gráfica de la pronunciación de determinadas regiones, como Andalucía, por ejemplo.

\subsection{El habla andaluza}

Lo que se conoce como variedad andaluza del español es más bien un conjunto de costumbres orales y vocabulario muy propios de Andalucía, a lo que los lingüistas, en general, suelen nombrar "hablas andaluzas", por la riqueza interna de cada zona de esta región. Se trata, por tanto, de una variedad diatópica.

Sin embargo, cabe resaltar que dichas costumbres orales coexisten, en cierta medida, sin mayores problemas con la norma culta. Dicho de otro modo, se entiende que un hablante

44 andaluz se sirve de la misma gramática que rige al español y que, al escribir, lo hace del mismo modo que los demás. Con todo, no haría falta recordar que la corrección o incorrección lingüística, ya sea en Andalucía o en cualquier otra región dependerá, mayormente, del nivel de instrucción escolar del hablante y de sus costumbres culturales.

Algunos de los rasgos caracterizan a los andaluces de algunas zonas, a saber: el 'seseo', fenómeno que consiste en la pronunciación de la 'C' (ante 'E', 'I') y de la 'Z' con sonido de 'S': seresa, en vez de cereza; sapato, en vez de zapato; la aspiración o la pérdida de la 'S': lo andaluce, en vez de los andaluces.

Otros trazos lingüísticos, a pesar de identificar a algunas zonas de Andalucía, son menos conocidos, de un modo general: vocales abiertas ( $d$, en vez de $d o s$ ); aspiración o relajación de la jota (picaón, en vez de picajón); la 'CH' aflojada (osho, em vez de ocho; bisho, en vez de bicho); sustitución de la 'L' por la 'R' (arma, en vez de alma); alternancia en las formas de tratamiento, o el uso de ambas formas de tratamiento a la vez (Vosotros/Utede sabéi qué tenéi que hacer, en vez de o bien Vosotros sabéis qué tenéis que hacer, o bien Ustedes saben qué tienen que hacer) y, en consecuencia, confusión en el uso de los pronombres (irsus, em vez de idos); cambio de género en algunas palabras (mucha calor, en vez de mucho calor).

Cabe destacar que muchos de estos trazos citados y otros no son un patrimonio lingüístico exclusivo de Andalucía, ya que igualmente se encuentran en otras regiones, tales 
como: la práctica de igualar la LL/Y, o yeísmo (yamar, en vez de llamar; rodiya, en vez de rodilla); elisión de la 'D', sobre todo en palabras con final ado e ido (cansao, en vez de cansado; partio, en vez de partido); elisión de algunas consonantes que se ubican al final de ciertas palabras $(U(s) t e ́$, en vez de Usted).

Presentamos, a continuación, un ejemplo del habla andaluza en la obra de Ruiz Zafón, en la cual nos basaremos para realizar nuestro análisis.

\subsection{Una muestra del habla andaluza en La Sombra del Viento, de Ruiz Zafón}

Hemos elegido para nuestro análisis un fragmento ${ }^{8}$ de La sombra del viento, de Ruiz Zafón (2001) en el que el autor reproduce gráficamente el habla del empleado de un café, situado junto al Teatro Poliorama, en Barcelona. La manera muy peculiar de comunicarse del camarero aguza la curiosidad de los personajes Bea y Daniel, lo que se convierte en una especie de juego de adivinanzas por dar con el lugar de origen de dicho camarero.

Saltan a la vista algunas diferencias muy marcadas entre el español que se considera estándar y el que utiliza el empleado. Pondremos, a continuación, algunas divergencias entre ambos, que se han observado. Para una mejor visualización, trataremos de poner la grafía usual entre paréntesis.

$\checkmark$ Aspiración de la 'S': vosotro (vosotros); utede (ustedes); soy (sois); lo (los), habéi (habéis); entrepane (entrepanes); chitorra (chistorra); frequísimo; (fresquísimo); ecabexe (escabeche); podéi (podéis); e (es); vierne (viernes); mimo (mismo); caretía (carestía); hemo (hemos).

$\checkmark$ Supresión de la 'D' intervocálica postónica: pedío (pedido); pueo (puedo); to (todo); tenío (tenido); sío (sido).

$\checkmark$ Pronunciación de la ' $\mathrm{S}$ ' en lugar de la ' $\mathrm{Z}$ ' -el seseo: diresión (dirección); ofresele (ofrecerles); consiensia (conciencia); partidaso (partidazo)

$\checkmark$ Sustitución de la 'L' por la 'R' (rotacismo): arbóndiga (albóndiga); borxevique (bolchevique); semifinar (semifinal).

$\checkmark$ Flojedad en la pronunciación de la ' $\mathrm{CH}$ ': ecabexe (escabeche); borxevique (bolchevique).

$\checkmark$ Añadidura de la 'G' al final de la palabra (alófono velarizado de la 'N' en posición implosiva): jamong (jamón).

$\checkmark$ Supresión de la 'B' (por asimiliación de los dos sonidos bilabiales): tamién (también). 
$\checkmark$ Supresión de la 'C': diresión (dirección); produto (producto).

$\checkmark$ Supresión de la ' $R$ ' al final de las palabras: ingerí (ingerir).

$\checkmark$ Confusión en el uso de los pronombres de tratamiento: vosotro (vosotros) / utede (ustedes).

$\checkmark$ Confusión en el uso de los pronombres de complemento indirecto, a causa de la confusión con las formas de tratamiento: comunicarsus (comunicaros, o comunicarles -según el pronombre de tratamiento).

El autor, deliberadamente, pone de relieve la característica local del habla del empleado a través de la confrontación con el español considerado estándar, utilizado por los personajes Bea y Daniel. Es más, Ruiz Zafón destaca el hecho de que se trata de un acento muy peculiar al establecer un juego entre los personajes Bea y Daniel, cuyo objetivo es identificar de dónde procede aquel acento. Bea propone que sería de Jaén (Andalucía), quizás porque coincide en algunas características, pero Daniel le afirma con seguridad que es oriundo de Coloma de Gramanet (Cataluña). Dicha afirmación tendría fundamento si se tiene en cuenta el fenómeno 46 de la emigración de andaluces hacia Cataluña en las décadas de los 50, 60 y 70, en busca de mejores oportunidades de vida.

\section{Acerca de los traductores de la obra}

Nuestro análisis trata de escudriñar la labor de dos traductores, a saber: Marcia Ribas, en la edición brasileña y José Teixeira de Aguilar, en la edición lusitana. Ambos, amablemente, se dispusieron a concedernos una rápida entrevista en la que quisimos indagar acerca de su formación y experiencia como profesional del par lingüístico español/portugués, además de las obras que han traducido.

\subsection{La traductora brasileña Marcia Ribas}

Marcia Cavalcanti Ribas Vieira, o Marcia Ribas, como suele firmar sus traducciones, es natural de Río de Janeiro (Brasil). Define su relación con el español como algo familiar, ya que su abuela materna, a quien solía visitar por periodos más largos o más cortos, desde que era niña, era argentina. Además, vivió en Santiago de Chile durante dos años.

En cuanto a su formación académica, tiene graduación en Ciencias Sociales (PUC-RJ), y máster en Letras, por la misma universidad. Revela no haber realizado estudios formales en Traductología, a excepción de un curso de subtitulado para películas. 
Entre sus traducciones publicadas, además de A sombra do vento, de Ruiz Zafón (2007), se destacan los siguientes trabajos: Dora Bruder (Dora Bruder), de Patrik Mondiano (Editora Rocco); A caravana da morte (Los zarpazos del puma), de Patricia Verdugo (Editora Revan); Ritos de morte (Ritos de muerte), de Alicia Giménez Bartlett (Editora Planeta do Brasil); O homem que falava de Octavia de Cádiz. (El hombre que hablaba de Octavia de Cádiz), de Alfredo Bryce Echenique (Editora Rocco).

\subsection{El traductor portugués José Teixeira de Aguilar}

José Teixeira de Aguilar, o J. Teixeira de Aguilar, como suele firmar sus traducciones, es natural de Lisboa (Portugal). Define su relación con el español como puramente afectiva, ya que su aproximación a esta lengua se dio a través de lectura de cómics, a la temprana edad de 11 ó 12 años.

En cuanto a su formación académica, afirma que muy poco tiene que ver con la traducción y confiesa no tener ninguna formación específica en el área, excepto por su participación en unos cuantos seminarios y acciones de formación. Posee licenciatura en Ciencias Militares (Marina) y fue oficial de la Marina de Guerra Portuguesa de 1966 a 2002.

Comenzó a traducir a finales del año 1970 y desde entonces ha sido una actividad prácticamente ininterrumpida, la cual asumió con mayor relevancia a partir del momento en el que dejó el trabajo activo en la Marina.

Entre sus más de ciento treinta traducciones publicadas, además de A sombra do Vento, de Carlos Ruiz Zafón (2013), figuran los nombres de grandes autores hispanoamericanos, tales como Mario Vargas Llosa, Guillermo Cabrera Infante, Gabriel García Márquez, Carlos Fuentes, Reinaldo Arenas, Pablo Neruda, Isabel Allende, Eduardo Mendoza, entre otros.

\section{Metodología y análisis de la actuación de los traductores}

A fin de facilitar el análisis contrastivo entre el español (ES) del TO y su traducción al portugués de Brasil (BR) y de Portugal (PT), pondremos a continuación, en paralelo, el fragmento que hemos elegido. Se destacarán en cursiva las peculiaridades orales del personaje representadas gráficamente, con el fin de facilitar su visualización. A continuación, presentaremos, por separado, el modus operandi de cada traductor implicado y sus respectivas soluciones para el problema de las superposiciones de lenguas y de la destrucción o la exotización de las redes lingüísticas vernáculas. 
Cuadro 1 - Contrastivo de un fragmento de La sombra del viento

\begin{tabular}{|c|c|c|}
\hline La sombra del viento - ES & A sombra do vento - BR & A sombra do vento - PT \\
\hline $\begin{array}{l}\text { Al poco, el encargado, un } \\
\text { tipo escuálido con mueca de } \\
\text { diablillo cojuelo, se acercó } \\
\text { a la mesa con aire oficioso. } \\
\text { - ¿Vosotro utede soy lo } \\
\text { que habéi pedío lo } \\
\text { entrepane de jamong? } \\
\text { Asentimos. } \\
\text {-Siento comunicarsus, en } \\
\text { nombre de la diresión, que } \\
\text { no queda ni veta de jamong. } \\
\text { Pueo ofresele butifarra } \\
\text { negra, blanca, mixta, } \\
\text { arbóndiga o chitorra. } \\
\text { Género de primera, } \\
\text { frequísimo. Tamién tengo } \\
\text { sardina en ecabexe, si no } \\
\text { podéi utede ingerí produto } \\
\text { cárnico por motivo de } \\
\text { consiensia religiosa. Como } \\
\text { e vierne... } \\
\text {-Yo con el café con leche } \\
\text { ya estoy bien, de verdad - } \\
\text { respondió Bea. } \\
\text {-Yo me moría de hambre. } \\
\text { - ¿Y si nos pone dos de } \\
\text { bravas? - dije. - Y algo de } \\
\text { pan también, por favor. } \\
\text {-Ora mimo, caballero. Y } \\
\text { utede perdonen la caretía } \\
\text { de género. Normalmente } \\
\text { tengo de to, hasta caviar } \\
\text { borxevique. Pero esta tarde } \\
\text { ha sío la semifinar de la } \\
\text { Copa Europa y hemo tenío } \\
\text { muchísimo personal. Qué } \\
\text { partidaso. } \\
\text { El encargado partió con } \\
\text { gesto ceremonioso. Bea lo } \\
\text { observaba, divertida. } \\
\text { - ¿De dónde es ese acento? } \\
\text { ¿Jaén? } \\
\text {-Santa Coloma } \\
\text { Gramanet - precisé. - Tú } \\
\text { coges poco el metro, } \\
\text { ¿verdad? }\end{array}$ & $\begin{array}{l}\text { Pouco depois, o gerente, um } \\
\text { sujeito esquálido com } \\
\text { expressão de diabinho } \\
\text { manco, aproximou-se da } \\
\text { mesa com ar cerimonioso. } \\
\text {-Foram vocês que } \\
\text { pediram a entrada de } \\
\text { presunto? } \\
\text { Assentimos. } \\
\text {-Sinto ter de lhes dizer, } \\
\text { em nome da direção, que o } \\
\text { nosso presunto acabou. } \\
\text { Posso lhes oferecer linguiça } \\
\text { preta, branca, mista, } \\
\text { almôndegas ou salsicha. } \\
\text { Mercadorias de primeira } \\
\text { fresquíssimas. Também } \\
\text { tenho sardinhas no óleo, se } \\
\text { os senhores não puderem } \\
\text { comer produtos de carne } \\
\text { por motivo de credo } \\
\text { religioso. Como hoje é } \\
\text { sexta-feira... } \\
\text {-Para mim basta o café com } \\
\text { leite, sério-respondeu Bea. } \\
\text { Eu estava com fome, } \\
\text { E se nos trouxer de entrada } \\
\text { umas batatinhas? E um } \\
\text { pouco de pão também, por } \\
\text { favor. } \\
\text {-Agora mesmo, senhores. E } \\
\text { perdoem a falta de } \\
\text { mercadorias. Em geral } \\
\text { tenho de tudo, até caviar } \\
\text { bolchevique. Mas esta tarde } \\
\text { foi a semifinal da Copa } \\
\text { Europa e tivemos uma } \\
\text { grande afluência. Que } \\
\text { jogaço. } \\
\text { O garçom se afastou com } \\
\text { gesto cerimonioso. Bea o } \\
\text { observava, achando graça. } \\
\text {-De onde é esse sotaque? } \\
\text { Jaén? precisei. - } \\
\text {-Santa Coloma } \\
\text { Gramanet - }\end{array}$ & $\begin{array}{l}\text { Daí a pouco o empregado, } \\
\text { um tipo esquálido com } \\
\text { máscara de diabrete, } \\
\text { aproximou-se da mesa com } \\
\text { ar oficioso. } \\
\text {-Foro os chores que pedira } \\
\text { a sande de presunto? } \\
\text { Fizemos que sim. } \\
\text {-Sinto munto comunicar- } \\
\text { les, em nome da drèção, } \\
\text { que já na temos nem uma } \\
\text { lasca de presunto. Posso } \\
\text { ofrecer-les choriço preto, } \\
\text { de carne, misto, almongas } \\
\text { ou chitorras (*). Géneros } \\
\text { de premeira, fesquíssimos. } \\
\text { Tamãe tenho sardinhas } \\
\text { descabeche, pró caso de na } \\
\text { poderem engerir produtos } \\
\text { de carne por motivos de } \\
\text { consçência regiosa. Comé } \\
\text { sexta-feira... } \\
\text {-Eu com o café com leite já } \\
\text { fico bem, palavra - } \\
\text { respondeu Bea. } \\
\text { Eu estava a morrer de fome. } \\
\text {-E se nos arranjasse duas de } \\
\text { batatas fritas com molho } \\
\text { picante - disse eu. - E um } \\
\text { pouco de pão também, por } \\
\text { favor. } \\
\text { - É pa já, cavalheiro. E } \\
\text { desculpem lá a falta de } \\
\text { géneros. Normalmente } \\
\text { tenho de tu, até caviá } \\
\text { bolchevique. Mas esta tarde } \\
\text { foi a semifinal da Taça } \\
\text { Doropa e caiu-nos cá um rô } \\
\text { de pessoal. Ca ganda jogo. } \\
\text { O empregado afastou-se } \\
\text { com ar cerimonioso. Bea } \\
\text { observava-o, divertida. } \\
\text {-De onde é este sotaque? } \\
\text { Jaén? - } \\
\text {-Santa Coloma } \\
\text { Gramanet - precisei. - Tu }\end{array}$ \\
\hline
\end{tabular}




\begin{tabular}{|c|c|c|}
\hline $\begin{array}{l}\text {-Mi padre dice que el metro } \\
\text { va lleno de gentuza y que, si } \\
\text { vas sola, te meten mano los } \\
\text { gitanos. (RUIZ ZAFÓN, } \\
\text { 2001, p.165-166). }\end{array}$ & $\begin{array}{l}\text { Você anda pouco de metrô, } \\
\text { não é? } \\
\text {-Meu pai diz que o metrô só } \\
\text { tem gentalha e que se você } \\
\text { estiver sozinha os ciganos } \\
\text { partem para o ataque. } \\
\text { (RUIZ ZAFÓN, 2007, } \\
\text { p.147). }\end{array}$ & $\begin{array}{l}\text { andas pouco de metro, não } \\
\text { andas? } \\
\text {-O meu pai diz que o metro } \\
\text { está cheio de gentalha e } \\
\text { que, se uma pessoa anda } \\
\text { sozinha, os ciganos lhe } \\
\text { deitam a mão. } \\
\text { * Chistorra é um enchido de } \\
\text { origem Navarra, com carne } \\
\text { de porco e de vaca, } \\
\text { entremeada e toucinho, que } \\
\text { se come principalmente } \\
\text { frito. A queda do «s» } \\
\text { corresponde à pronúncia } \\
\text { peculiar do indivíduo. (N. } \\
\text { T.). (RUIZ ZAFÓN, 2013, } \\
\text { p.190-191). }\end{array}$ \\
\hline
\end{tabular}

Fuente: elaboración propia.

\subsection{Acerca de la actuación de los traductores}

Es importante que se observe, ante todo, la riqueza del material que se nos presenta. Se trata de dos actuaciones, con soluciones totalmente distintas para el mismo problema que se les plantea a los traductores.

\subsubsection{Acerca de la actuación de la traductora brasileña Marcia Ribas}

En la traducción brasileña, Marcia Ribas actúa, tal y como prevé Berman en lo que concierne al borramiento (sic.) de las superposiciones de lenguas y la destrucción de las redes lingüísticas vernáculas. Al presentar un registro en portugués estándar y libre de cualquier clase de "extrañeza", le ofrece al lector la falsa ilusión de que se trata de un texto tan brasileño como el de cualquier autor nacional.

En pro de construir un texto homogéneo, la traductora no vacila en barrer del TM, por completo, cualquier trazo del habla andaluza: no la exotiza a través de cursiva o comillas; no la vulgariza, ni la ridiculiza, a través de otro modo de hablar peculiar de grupos específicos de la lengua meta (LM). En definitiva, torna invisible el habla andaluza en el TM de tal modo que el lector final ni siquiera es capaz de identificar cualquier rastro de dicha variedad lingüística.

De este modo, todos los personajes involucrados se manifiestan, lingüísticamente, del mismo modo, utilizando el mismo lenguaje estandarizado que cualquier brasileño común. En realidad, es como si siempre hubieran pertenecido a la misma comunidad sociocultural sin que 
se presente, en ningún momento, cualquier indicio de desvío de la norma por parte del camarero.

La impresión que nos da es la de que el empleado siempre ha pertenecido al mismo universo cosmopolita de la pareja de adolescentes a la que sirve. Lo único que los diferencia es la postura oficial de respeto que adopta el camarero - una mera exigencia de su trabajo- en la forma de tratar a sus jóvenes clientes.

Ahora bien, hay un detalle en la traducción de Marcia Ribas que va en contra de la postura que adopta de limpiar el TM de las "impurezas" del TO. El hecho de que no haya ninguna mención -gráficamente en portugués-al modo en que se expresa el camarero, genera un problema del que, quizás, no se haya dado cuenta. Concretamente, su toma de decisión convierte la petición de información que se materializa en la sentencia: "De onde é esse sotaque? Jaén?" en algo suelto, carente de conexión con el contexto.

Desde esta perspectiva habría que mencionar a Meschonnic (2010) y su poética del traducir, en lo que atañe a la unidad de traducción. Según este autor, la unidad de traducción literaria es el discurso. Al tener clara la importancia del lenguaje, la unidad de traducción ya no 50 puede fijarse en las unidades de la lengua, sino en el conjunto, como un todo. Al fin y al cabo, la literatura se construye en el marco del discurso y reclama conceptos del discurso. Por ello, la traducción es el punto más débil en el que se confunden lengua y discurso más a menudo, y en ocasiones, desastrosamente.

De ser así, o bien la traductora se da al trabajo de introducir, de algún modo, las peculiaridades del habla del camarero y, en consecuencia, abre espacio en el TM para mencionar su acento; o bien, no incluye en el texto todas las representaciones del modo particular de comunicarse del camarero y, de esta manera no se ve en la obligación de mencionar su acento. Se trata de una cuestión de cohesión. En definitiva, el hilo que se utiliza para hilvanar el discurso es la cohesión.

\subsubsection{Acerca de la actuación del traductor lusitano José Teixeira de Aguilar}

En la traducción lusitana, J. Teixeira de Aguilar recorre el camino a la inversa. Destaca la extrañeza del acento del camarero a través de distintas soluciones. Fundamentalmente, se sirve de una representación gráfica incorrecta. A fin de que se pueda establecer la diferencia entre las dos formas, pondremos la normativa entre paréntesis: munto (muito); foro (foram); chôres (senhores); pedira (pediram); les (lhes); drèção (direção); choriço (chouriço); almongas (almôndegas); premeira (primeira); fesquíssimos (fresquíssimos); tamãe (também); scabeche 
(escabeche); pró (como reducción de 'para o'); engerir (ingerir); conçência (consciência); regiosa (religiosa); comé (como reducción de 'como é'); caviá (caviar).

En menor proporción, J. Teixeira de Aguilar emplea en su traducción la reducción de palabras: sande (reducción de sanduíche); pa (para); tu (tudo); na (nada); rô de pessoal (supuesta reducción fónica de 'horror' de pessoal') para expresar una gran cantidad de personas. Asimismo, recurre a la estrategia a la inversa de aglutinar palabras: doropa (de Europa).

Con el fin de demostrar la singularidad de la palabra "chitorra" (sic.), el traductor maneja una combinación de dos estrategias. En un primer momento recurre al préstamo para, luego, ponerle un asterisco y su correspondiente nota a pie de página. En dicha nota, trata de informar al lector, doblemente, de que la chistorra es un tipo de embutido de origen navarro y que la caída de la ' $\mathrm{S}$ ' corresponde a la pronunciación peculiar del personaje.

En el caso de la traducción del original "Qué partidaso", J. Teixeira de Aguilar emplea una expresión típicamente popular, que se ha incorporado al portugués lusitano, a través del habla angolana. "Ca ganda” correspondería a algo grandioso, estupendo. Así que "Ca ganda jogo” concerniría a “Que grande jogo” (¿Qué partidazo!, en español).

Con el fin de resumir la actuación de J. Teixeira de Aguilar, es loable reconocer que, de ninguna manera, éste ignora la presencia del habla andaluza en el TO. Al revés, procura destacar insistentemente que hay algo extraño en el habla del camarero y que ello necesita figurar en el TM. Con todo, al concretar su intento, lo hace a través de dos prácticas que condena Berman, a saber: la "vulgarización"9 en el ámbito de la destrucción de las redes lingüísticas vernáculas; y el borramiento (sic.) de las superposiciones de lenguas.

La vulgarización se pone de manifiesto a través de la sustitución de la representación gráfica del habla de determinada comunidad lingüística del TO, por otra del TM. Al hacerlo, el traductor acaba por borrar del TM la presencia del habla andaluza, al menos, en lo que respecta a la representación gráfica del modo peculiar de comunicarse esa gente. De esta manera, el lector final más atento solo se dará cuenta de las superposiciones de lenguas del TO y presencia andaluza en dos momentos: 1) cuando se menciona la "chistorra" y su respectiva nota a pie de página; 2) cuando los personajes Bea y Daniel hacen alguna referencia a Jaén (Andalucía) y a Santa Coloma de Gramanet (Cataluña). En ello radica el problema.

La homogeneización que anhela el traductor se manifiesta a medias, si se observa la incongruencia que se instala en el TM. En concreto, éste pone en boca de andaluces 
incorrecciones, reducciones de palabras, aglutinaciones y expresiones que no son propias de aquella región.

\section{Conclusiones}

De un modo general, las trece tendencias deformantes de las que hemos tratado, incluidas aquellas de las que nos ocupamos en nuestro análisis, forman parte de una práctica, muchas veces inconsciente, del traductor en pro del sentido.

Lo cierto es que consciente o inconscientemente, el traductor va destruyendo paulatinamente las sutilezas que le confieren a la obra original su estatus literario y al que Berman resume en un único término: "letra".

La inconsciencia a la que nos referimos nace del hecho de que el traductor se encuentra constantemente sometido a un bombardeo de voces, oriundas del sentido común o de las teorías más tradicionales, que le inculcan la persecución del sentido como objetivo principal. Con la excusa de alcanzar dicho objetivo, se le permite todo, incluso sacrificar algún elemento fundamental del TO a fin de conferir homogeneidad al texto.

Claro está que una escritura, supuestamente homogénea y libre de "impurezas", no comportaría extrañezas representadas por préstamos lingüísticos, ni mucho menos por la manera muy peculiar de manifestarse de ciertos personajes en sus redes lingüísticas vernáculas. Por más condescendiente que fuera el traductor, presentándolos en cursiva o entre comillas, aún así seguiría siendo una demostración de heterogeneidad. De ser así, comprendemos ser ésta la línea de raciocinio adoptada por la traductora brasileña.

La estrategia del traductor lusitano de crearle al camarero en la LM un modo de comunicarse en el que se mezclan representación gráfica incorrecta de ciertas palabras, reducciones o aglutinaciones, préstamos y expresiones provenientes del habla angolana, tampoco parece cuadrar con los postulados de Berman. En opinión de este estudioso de la traducción literaria, solo pueden traducirse las lenguas cultas. Desde esta perspectiva, considera vulgar transponer giros y modos de hablar propios de ciertos grupos de la LO por otros de la LM. Hacerlo solo ridiculizaría el original.

De todos modos, bajo la óptica de la ética bermaniana, ni la brasileña, ni el lusitano adoptan una postura que acoja al otro en cuanto otro. Cada uno, a su manera, procura "disfrazar" al otro, amenizándole lo que tiene de más "extravagante" o "pintoresco", con el fin de que el lector final lo tome como algo de su propio país. Por un lado, la primera construye un texto como si fuera un original nacional, al no establecer ninguna divergencia entre las hablas de los 
personajes. Por otro, el segundo, igualmente, erige un texto como si fuera nacional, arrebatando con tintes propios de su país y cultura lo que es propio del universo andaluz.

A decir verdad, Berman discute, en varios niveles, la problemática de la deformación en la traducción literaria y su falta de ética sin, con ello, ofrecer al traductor una receta que garantice el éxito de esta labor. En cierto modo, la actitud adoptada por este autor corresponde a la realidad que afrontan los traductores, ya que no hay una receta que enseñe cómo traducir bien. Cada traducción, sobre todo la literaria, es un nuevo universo que desvelar y, a la vez, un nuevo reto, cuyos problemas y respectivas soluciones se renuevan constantemente.

En realidad, este trabajo no ha tenido como objetivo emitir juicios de valor, ni tampoco señalar errores, sino reflexionar sobre los problemas y soluciones de la traducción literaria. Con ello, esperamos haber contribuido a que el traductor realice una tarea consciente en su toma de decisiones y las consecuencias que cada una de ellas acarrea. Creemos que cada profesional de la traducción actúa, según sus propios valores éticos y conocimientos tanto de la LO como de la LM. Asimismo, opinamos que toda traducción es válida y cumple, de algún modo, el papel que le toca.

\section{REFERENCIAS BIBLIOGRÁFICAS}

BERMAN, Antoine. La traducción y la letra o el albergue de lo lejano. Traducido por Ignacio Rodríguez. 1. ed. Buenos Aires: Dedalus Editores, 2014. 160 p.

KOINÉ. En: Diccionario de la lengua española. 23. ed. Real Academia Española, 2014. Disponible en https://dle.rae.es/?id=Mi9J3sc. Consultado el 1 out.19.

MESCHONNIC, Henri. Poética do traduzir. Traducido por Jerusa Pires Ferreira e Suely Fenerich. São Paulo: Perspectiva, 2010. Impreso. 279 p.

RUIZ ZAFÓN, Carlos. La Sombra del Viento. Barcelona: Círculo de Lectores (por Cortesía de Editorial Planeta), 2001. Impreso. 445 p.

RUIZ ZAFÓN, Carlos. A sombra do vento. Traducido por Marcia Ribas. Rio de Janeiro: Editora Objetiva, 2007. Impreso. 399 p.

RUIZ ZAFÓN, Carlos. A sombra do vento. 23. ed. Traducido por José Teixeira de Aguilar. Lisboa: Publicações Dom Quixote, 2013. Impreso. 507 p.

\footnotetext{
* Luis Carlos RAMOS-NOGUEIRA - Doutor em Linguística Geral e Teoria da Literatura (2017) pela Universidade de Granada, Espanha. Mestre em Linguística Aplicada (2008) pela Universidade de Brasília. Especialista em Tradução Espanhol / Português / Espanhol (2012) pela Universidade Gama Filho (UGF). Especialista em Metodologia de Ensino da Língua Espanhola (2006) pelo Instituto Brasileiro de Pós-Graduação e
} 
Extensão (IBPEX). Graduado em Letras Português/Espanhol (2006) pela Universidade Centro Unificado de Brasília (UNICEUB). Professor da Universidade de Brasília. Brasília, Distrito Federal, Brasil.

Currículo acadêmico: http://lattes.cnpq.br/0001380421706934

ORCID: https://orcid.org/0000-0001-9832-9434

E-mail: luiscarlos.lucanog@ gmail.com

${ }^{1}$ Las reflexiones de este artículo forman parte de los estudios realizados en el ámbito de la tesis doctoral titulada La traducción de la fraseología en la obra de Carlos Ruiz Zafón en el par lingüístico español-portugués, dirigida por los profesores doctores Juan de Dios Luque Durán y José Manuel Pazos Bretaña, presentada al Programa Lenguas, Textos y Contextos, del Departamento de Linguística General y Teoría de la Literatura, de la Universidad de Granada (ES), en 2017.

${ }^{2}$ Aunque nos parezcan más adecuados los términos "supresión” o "eliminación”, reproducimos aquí el que utiliza el traductor Ignacio Rodríguez, en la edición argentina de La Traduction et la Lettre ou l'Auberge du Loitain: BERMAN, A. La traducción y la letra o el albergue de lo lejano. 1. ed. Buenos Aires: Dedalus Editores, 2014. ${ }^{3}$ Cabe aclarar que, conscientes de la existencia de alguna divergencia en lo que concierne a la terminología que se utiliza en la traducción de un sinfín de neologismos de Berman, aquí -y en otros casos-, procuramos conservar la misma terminología que se ha utilizado en la edición argentina, utilizada en el marco teórico.

${ }^{4}$ Entiéndase "extraño" y sua variación "extrañeza" no de un modo negativo, sino como algo novedoso -y a la vez, problemático-, que no se puede reconocer.

${ }^{5}$ Lengua común que resulta de la unificación de ciertas variedades idiomáticas (DRAE).

${ }^{6}$ Cabe aclarar que, si Berman se refiere a la obra maestra de Guimarães Rosa, Grande Sertão Veredas, los escenarios muchas veces ficticios que describe, pueden ubicarse tanto en Bahia (noreste), como en Minas Gerais (sureste).

${ }^{7}$ Primera edición de 2001, por Editorial Círculo de Lectores, Barcelona.

${ }^{8}$ Consúltese el fragmento completo en español en el apartado 5. Metodología y análisis de la actuación de los traductores.

${ }^{9}$ Término utilizado por Berman. 